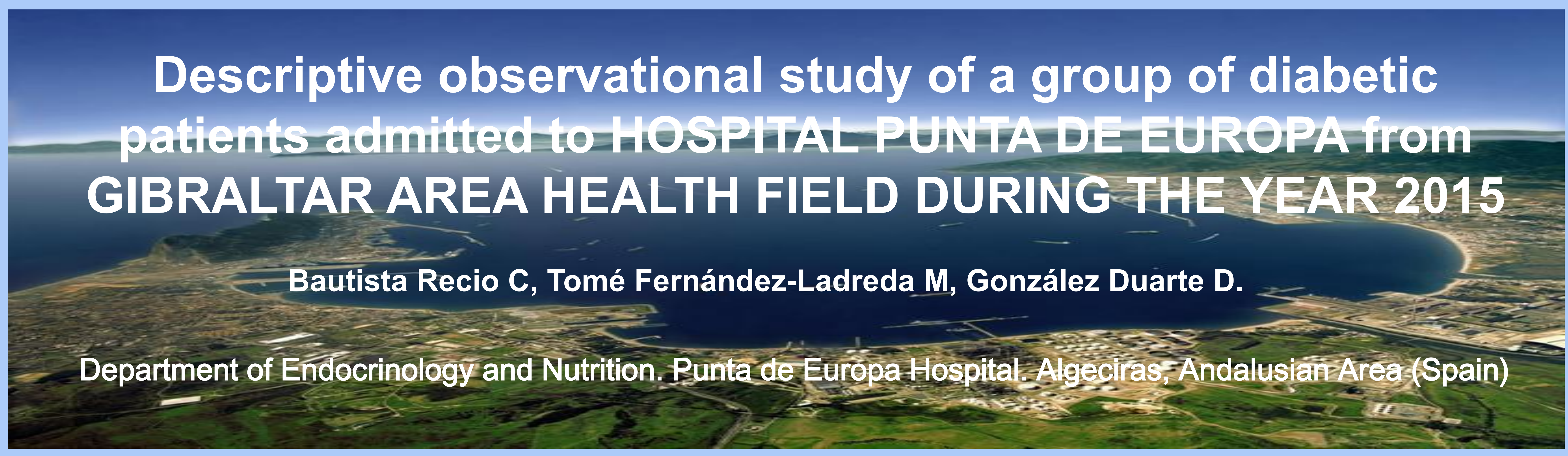

\section{OBJECTIVES}

Objectives: The prevalence of diabetic patients admitted in hospitals close to 20 $\%$ in some series. Our goal is to determine the prevalence of diabetic patients assessed by interclinical calls from different medical and surgical specialties that have been entered during 2015 in our Hospital, in order to describe the characteristics that these diabetic patients.

\section{MATERIAL AND METHODS}

Material and methods. We present 116 patients evaluated by interclinical consultation request form from different medical and surgical specialties. The patients were admitted in Algeciras Hospital (Gibraltar Health Area) during 12 months - period beginning from 1 January to 31 December 2015-. We have determined the different quantitative and qualitative variables: source of income, sex, age, type of diabetes, average length of stay.

\title{
Summary of Results
}

AVERAGE LENGTH OF STAY (DAYS)
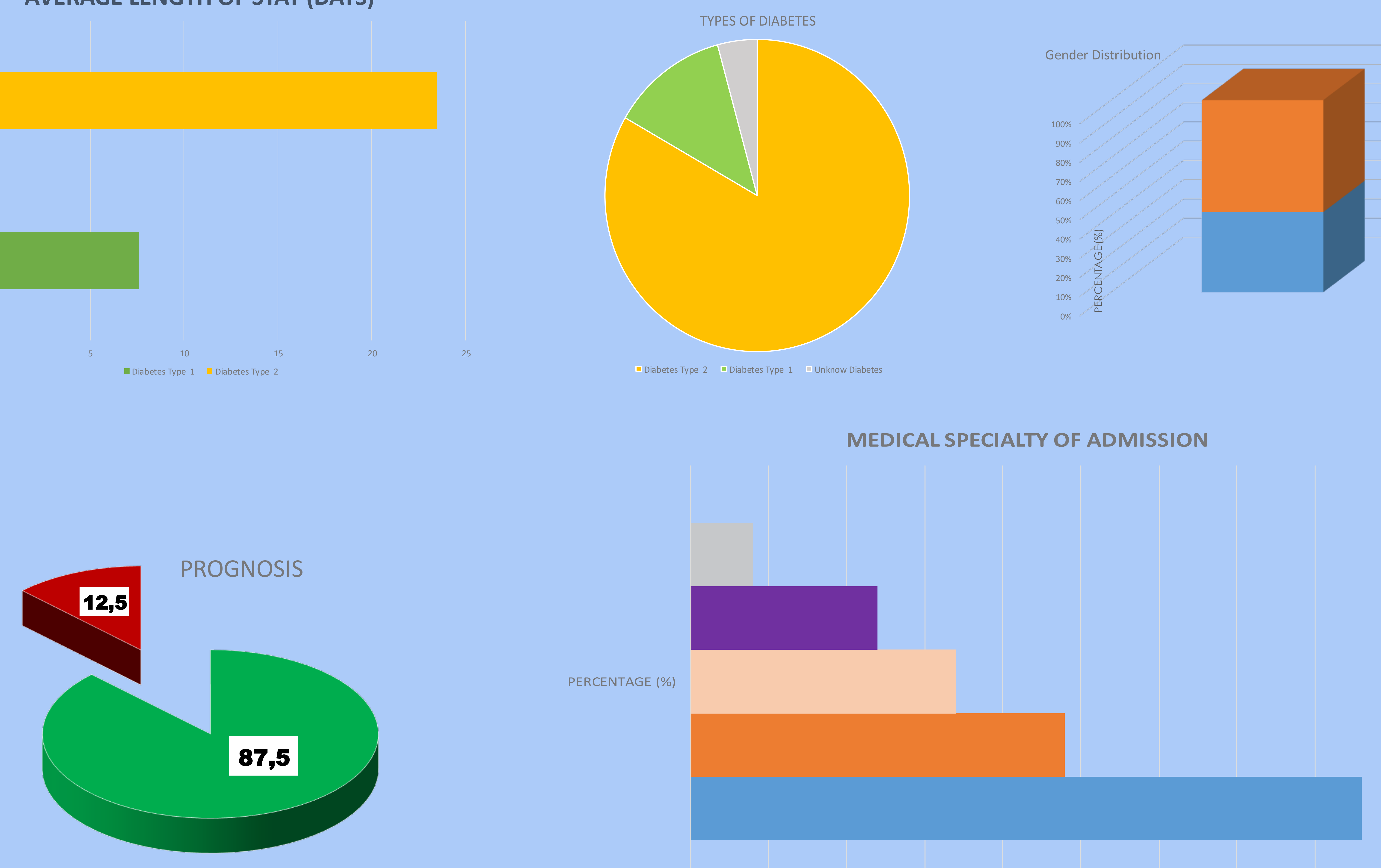

Conclusions :- The Endocrinology Unit of Punta Europa Hospital (Gibraltar Health Area) received an average of 9.7 interclinical calls per month in 2015, in order to assessment of hyperglycemia in diabetic patients, either secondary to diabetes known as metabolically decompensated or in patients with no known diabetes before to admission. Hyperglycemia is a common finding in hospitalized patients. It's associated with increased days of hospital stay, morbidity and mortality. 